\title{
Fitossociologia de plantas daninhas em área de patoreio no Município de Caturité, Região do Cariri Paraibano, Brasil
}

\section{Emannuella Hayanna Alves de Lira' ${ }^{1}$, Bartolomeu Israel de Souza $^{2}$ e Suenildo Jósemo Costa Oliveira ${ }^{3}$}

\author{
${ }^{1}$ Universidade Federal da Paraíba. Centro de Ciências Exatas e da Natureza. \\ Programa de Pós-Graduação em Desenvolvimento e Meio Ambiente. Campus \\ Universitário. João Pessoa-PB, Brasil (CEP 58051-900). *E-mail: \\ emannuellahayanna@gmail.com. \\ ${ }^{2}$ Universidade Federal da Paraíba. Centro de Ciências Exatas e da Natureza. \\ Departamento de Geociências. Campus Universitário. João Pessoa-PB, Brasil \\ (CEP 58051-900). \\ ${ }^{3}$ Universidade Estadual da Paraíba. Centro de Ciências Agrárias e Ambientais. \\ Lagoa Seca-PB, Brasil (CEP 58117-000).
}

Resumo. As infestações de plantas daninhas em áreas de pastoreio representam fator limitante a sustentabilidade da atividade pecuária com consequente aumento dos custos de produção e menor rentabilidade do produto. Diante deste fato, este trabalho teve como objetivo caracterizar a composição florística e as relações fitossociológicas de plantas daninhas em área de pastoreio no Município de Caturité-PB, visando à manutenção da pecuária como atividade economicamente viável e a conservação da vegetação local. Para isto foi utilizado o Método do Quadrado Ocupado, lançando aleatoriamente por 20 vezes na área de interesse um quadrado vazado nas dimensões $1 \times 1=1 \mathrm{~m}^{2}$. As plantas daninhas presentes foram quantificadas e identificadas e para efeito dos cálculos fitossociológicos foram analisando os seguintes parâmetros, Quadrado Ocupado, Número de Indivíduos, Frequência, Frequência Relativa, Densidade, Densidade Relativa, Abundância, Abundância Relativa e Índice de Importância Relativa. No total foram quantificados 3.670 indivíduos, distribuídos em 10 famílias e 17 espécies. As famílias botânicas de plantas daninhas mais representativas na área foram Poaceae, Asteraceae e Amaranthaceae. Entre as espécies daninhas identificadas na pastagem foi constatada uma distribuição irregular, indicando a presença de grande concorrência entre as populações daninhas e evidenciando uma degradação da área. As espécies Cyperus rotundus L., Xanthium strumarium L. e Brachiaria decumbens cv. Basilisk, destacaram-se como aquelas que merecem maior atenção no controle.
Recebido

09/02/2020

Aceito

28/04/2020

Publicado

$30 / 04 / 2020$

Acesso aberto

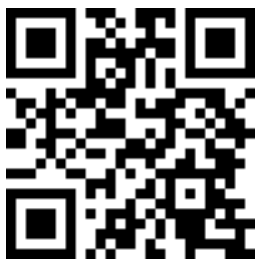

ORCID

(D) 0000-0003-4403-9487 Emannuella Hayanna Alves de Lira 
Palavras-chave: Degradação de pastagens; Pecuária; Cyperus rotundus; Xanthium strumarium; Brachiaria decumbens cv. Basilisk.

\begin{abstract}
Weed phytosociology in grazing area in the Municipality of Caturité, Cariri Region of Paraíba, Brazil. Weed infestations in grazing areas represent a limiting factor in the sustainability of livestock activities with a consequent increase in production costs and lower product profitability. Given this fact, this work aimed to characterize the floristic composition and the phytosociological relationships of weeds in a grazing area in the Municipality of Caturité, State of Paraíba, Northeast Brazil, aiming at maintaining livestock as an economically viable activity and the conservation of local vegetation. For this, the Occupied Square Method was used, randomly casting a hollow square in the dimensions of $1 \times 1=1 \mathrm{~m}^{2} 20$ times in the area of interest. The weeds present were quantified and identified and for the purpose of phytosociological calculations the following parameters were analyzed: Occupied Square, Number of Individuals, Frequency, Relative Frequency, Density, Relative Density, Abundance, Relative Abundance and Relative Importance Index. In total 3,670 individuals were quantified, distributed in 10 families and 17 species. The most representative botanical families of weeds in the area were Poaceae, Asteraceae and Amaranthaceae. Among the weeds identified in the pasture, an irregular distribution was found, indicating the presence of great competition among the weeds and evidencing a degradation of the area. The species The species Cyperus rotundus L., Xanthium strumarium L. and Brachiaria decumbens cv. Basilisk, stood out as those that deserve more attention in control.
\end{abstract}

Keywords: Degradation of pastures; Livestock; Cyperus rotundus; Xanthium strumarium; Brachiaria decumbens cv. Basilisk.
D $0000-0003-2173-8314$

Bartolomeu Israel de Souza

(ㄱ) 0000-0002-7591-4806 Suenildo Jósemo Costa Oliveira

\section{Introdução}

O semiárido brasileiro é constituído por caatingas onde predominam temperaturas médias anuais elevadas e constantes, com chuvas escassas e concentradas entre 3 a 4 meses do ano (Ab'Saber, 2003). Inserida neste espaço geográfico, encontra-se a Microrregião do Cariri Paraibano que possui dentre suas principais características solos predominantemente rasos e salinos (Travassos, 2012).

Dentre as atividades humanas desenvolvidas nesta região destaca-se o sistema agropecuário que tem como característica a ocupação dos solos pelos rebanhos bovino e caprino-ovino, bem como, o desenvolvimento da agricultura sazonal ou em sequeiro (Silva e Silva, 2016). Destaca-se que a pecuária leiteira tem se efetivado como uma atividade econômica estratégica para o cariri paraibano representando uma grande bacia leiteira do Estado da Paraíba (Bezerra, 2016).

0 regime de criação dos rebanhos nessa região é na maioria dos casos o extensivo e o semi-extensivo, onde a pastagem nativa é utilizada na alimentação animal (Galvão Junior et al., 2015). Esse sistema de criação, aliado aos fatores físicos e químicos limitantes 
característicos da região e ao histórico de degradação têm contribuído para a perda da diversidade florística e consequente desertificação da Caatinga (Luna et al., 2018).

De acordo com Paulino et al. (2012) cerca de $80 \%$ das pastagens brasileiras tem algum nível de degradação, representando fator limitante a sustentabilidade da atividade pecuária em regiões tropicais e subtropicais, tendo em vista que pode ocasionar grandes reduções na produtividade dos rebanhos. Essa degradação das pastagens pode ser inicialmente percebida pelo aumento no número de plantas daninhas em detrimento ao capim, sendo assim a identificação das plantas daninhas em pastagens é forte indicativo de degradação local (Motta et al., 2012; Dias-Filho, 2017).

Apesar da clara importância de se identificar as espécies daninhas presentes nas pastagens brasileiras tendo em vista que esses estudos podem subsidiar estratégias de controle capazes de melhorar o gerenciamento dessas espécies, pouco se sabe sobre as espécies daninhas que ocorrem em pastagens no nordeste do Brasil (Costa e Mesquita, 2016).

Conforme Oliveira et al. (2018) a identificação das espécies de plantas daninhas nos sistemas agropecuários é de grande valia, pois, a partir desse conhecimento o manejo dessas espécies é otimizado, através da escolha de métodos de controle com eficiência sobre a maior parte das espécies daninhas presentes na área.

o Município de Caturité, localizado no Cariri paraibano, é um dos principais produtores de leite bovino do estado, sendo a atividade pecuária de grande importância na conjuntura local (Aguiar et al., 2019). Por esse motivo é de grande relevância para a região o conhecimento da fitocenose das áreas de pastoreio visando tanto à manutenção da pecuária como atividade economicamente viável, como à conservação da vegetação local. Neste contexto, este trabalho teve como objetivo caracterizar a composição florística e as relações fitossociológicas de plantas daninhas em área de pastoreio no município de Caturité-PB.

\section{Material e métodos}

0 estudo foi realizado em área de pastoreio de uma propriedade rural localizada no Município de Caturité, Estado da Paraíba, situado na Região do Cariri Oriental, com área de $118,2 \mathrm{~km}^{2}$, à latitude $-7^{\circ} 24^{\prime} 47^{\prime \prime}$ Sul, longitude $-36^{\circ} 1^{\prime} 49^{\prime \prime}$ Oeste e altitude de $415 \mathrm{~m}$, distante $160 \mathrm{~km}$ da Capital João Pessoa (Cidade Brasil, 2019). De clima semiárido, com temperaturas máximas de $37^{\circ} \mathrm{C}$ e mínimas de $16^{\circ} \mathrm{C}$ e precipitação pluviométrica média de $500 \mathrm{~mm} /$ anual. Com população estimada em 4.852 habitantes, majoritariamente rural (IBGE, 2019).

O levantamento da comunidade de plantas daninhas infestante foi feito através do método do Quadrado Ocupado, que consiste em lançar aleatoriamente na área de interesse um quadrado vazado nas dimensões $1 \times 1=1 \mathrm{~m}^{2}$, conforme metodologia adaptada de Brandão et al. (1998), Brighenti et al. (2003), Lara et al. (2003), Tuffi Santos et al. (2004) e Braun-Blanquet (1979).

$\mathrm{Na}$ área em estudo foram realizados um total de 20 lances, perfazendo uma área total de $20 \mathrm{~m}^{2}$. As plantas daninhas presentes em cada quadrado foram quantificadas e identificadas quanto a espécie através de literatura especifica (Lorenzi, 2014) e consulta a especialistas. As espécies foram classificadas nas famílias de acordo com o sistema APG III (Angiosperm Phylogeny Group). Após a quantificação e classificação por famílias e espécies, os dados coletados foram tabulados em planilha do Excel ${ }^{\circledR}$, para efeito dos cálculos fitossociológicos e confecção dos Gráficos e Tabelas analisando os seguintes parâmetros:

- Quadrado Ocupado $(\mathrm{QO})=>\mathrm{QO}=$ quantidade de lances em que apareceu a espécie. 
-Número de Indivíduos (NI)=> NI= № de indivíduos coletados nos lances.

- Frequência $(\mathrm{F})=>\mathrm{F}=\mathrm{QO} / \mathrm{N}$ o total de lances.

-Frequência Relativa $(\mathrm{Fr} \%)=>\mathrm{Fr} \%=(\mathrm{F} \mathrm{X} \mathrm{100}) / \Sigma \mathrm{F}$

- Densidade $\left(\mathrm{Dm}^{-2}\right)=>\mathrm{Dm}^{-2}=(\mathrm{NI} X \mathrm{~F}) / \mathrm{QO}$

- Densidade Relativa $\left.(\mathrm{Dr} \%)=>\mathrm{Dr} \%=\left(\mathrm{Dm}^{-2}\right) \mathrm{X} 100\right) / \Sigma \mathrm{Dm}^{-2}$

- Abundância $(\mathrm{A})=>\mathrm{A}=\mathrm{NI} / \mathrm{QO}$

- Abundância Relativa $(\mathrm{Ar} \%)=>\operatorname{Ar} \%=(\mathrm{AX} 100) / \Sigma \mathrm{A}$

- Índicede Importância Relativa $(\operatorname{Ir} \%)=>\operatorname{Ir}(\%)=\Sigma \mathrm{Fr}+\mathrm{Dr}+\mathrm{Ar}$

\section{Resultados e discussão}

Os resultados da análise florística da comunidade de plantas daninhas em área de pastoreio no cariri paraibano podem ser observados na Tabela 1 . No total foram quantificados 3.670 indivíduos, distribuídos em 10 famílias e 17 espécies, que estão listadas por nome científico e comum de acordo com suas respectivas famílias.

Tabela 1. Espécies de plantas daninhas e suas respectivas famílias identificadas em área de pastoreio no Município de Caturité, Cariri paraibano.

\begin{tabular}{|c|c|c|}
\hline Família & Espécie & Nome Popular \\
\hline Amaranthaceae & $\begin{array}{l}\text { Amaranthus viridis } \mathrm{L} . \\
\text { Chenopodium ambrosioides } \mathrm{L} .\end{array}$ & $\begin{array}{l}\text { Bredo } \\
\text { Erva Santa Maria }\end{array}$ \\
\hline Asteraceae & $\begin{array}{l}\text { Bidens sulphurea (Cav.) Sch. Bip. } \\
\text { Tagetes minuta L. } \\
\text { Xanthium strumarium L. }\end{array}$ & $\begin{array}{l}\text { Picão-grande } \\
\text { Cravo-de-defunto } \\
\text { Espinho-de-carneiro }\end{array}$ \\
\hline Convolvulaceae & Ipomoea purpurea L. & Corda-de-viola \\
\hline Cyperaceae & Cyperus rotundus L. & Tiririca \\
\hline Euphorbiaceae & Ricinus communis L. & Mamona \\
\hline Fabaceae & $\begin{array}{l}\text { Senna obtusifolia (L.) Irwin \&Barneby } \\
\text { Mimosa pudica L. }\end{array}$ & $\begin{array}{l}\text { Mata-pasto } \\
\text { Malicia }\end{array}$ \\
\hline Malvaceae & Malva sylvestris L. & Malva \\
\hline Poaceae & $\begin{array}{l}\text { Echinochloa crusgalli (L.) P.Beauv. } \\
\text { Brachiaria decumbens cv. Basilisk } \\
\text { Cenchrus echinatus L. (CCHEC) } \\
\text { Eleusine indica (L.) Gaertn (ELEIN) }\end{array}$ & $\begin{array}{l}\text { Capim-arroz } \\
\text { Capim-braquiária } \\
\text { Capim-carrapicho } \\
\text { Capim-pé-de-galinha }\end{array}$ \\
\hline Rubiaceae & Richardia brasiliensis (Gomes) & Poaia-do-campo \\
\hline Verbenaceae & Vitex agnus castus L. & Liamba \\
\hline
\end{tabular}

Das 10 famílias botânicas de plantas daninhas identificadas na área estudada (Amaranthaceae, Asteraceae, Convolvulaceae, Cyperaceae, Euphorbiaceae, Fabaceae, Malvaceae, Poaceae, Rubiaceae e Verbenaceae) verificou-se maior representatividade da família Poaceae dentro da comunidade com um total de quatro espécies, seguida da família Asteraceae com três espécies, e das famílias Amaranthaceae e Fabaceae, ambas com 2 espécies (Figura 1), juntas essas famílias representam 64,70\% do total de espécies daninhas encontradas na localidade.

A predominância de espécies daninhas das Famílias Poaceae e Asteraceae como infetantes nos sistemas agropecuários já foi observada por outros autores (Lamengo et al., 2015; Rodrigues et al., 2017; Dominschek et al., 2019). De acordo com Braga et al. (2012) estas duas famílias estão entre as mais representativas quando se fala em plantas 
daninhas na lavoura e na pecuária, sendo por esse motivo consideradas as principais famílias de plantas daninhas do Brasil (Oliveira e Freitas, 2008).

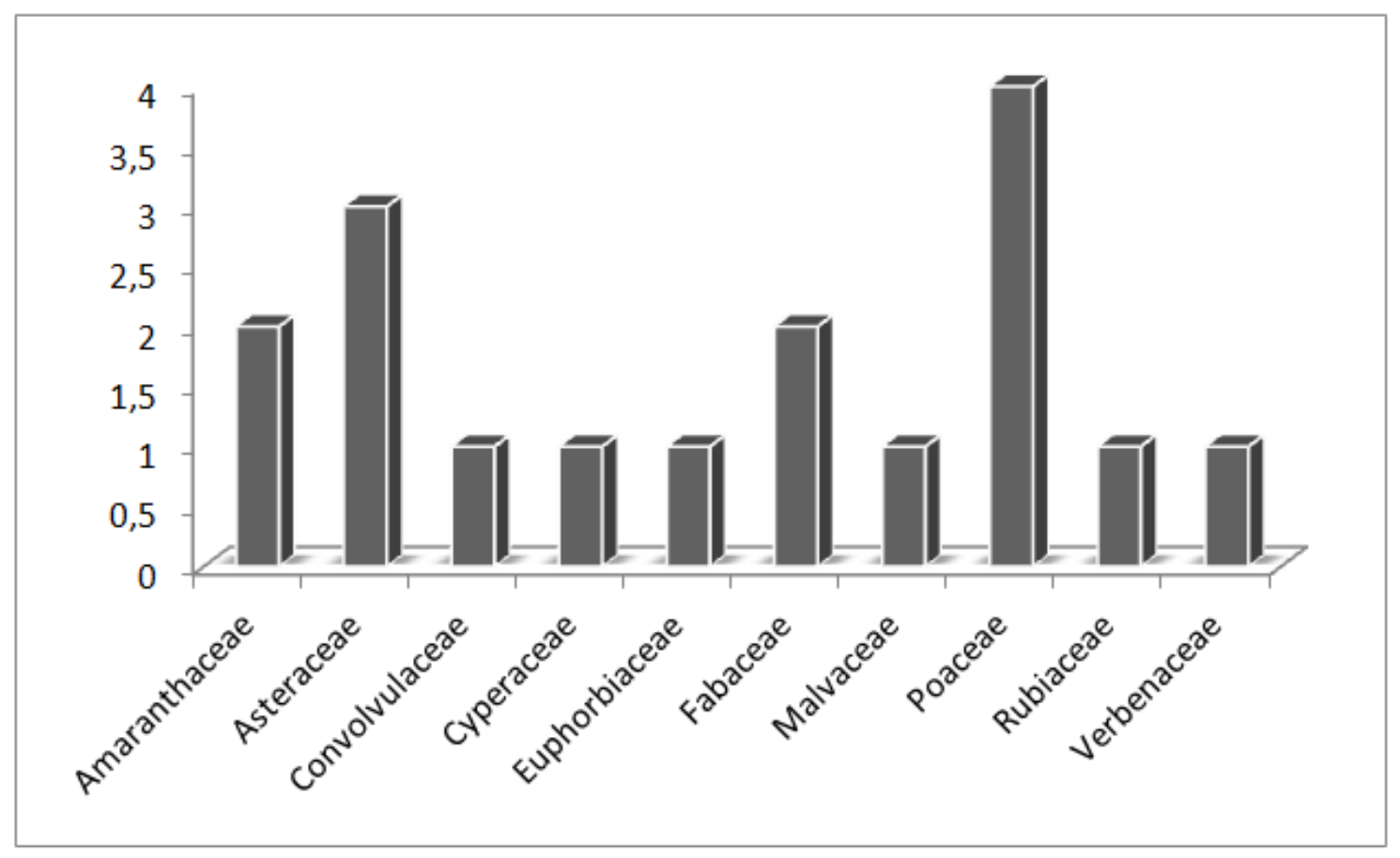

Figura 1. Distribuição das Famílias botânicas de plantas daninhas encontradas em área de pastoreio no município de Caturité, Cariri paraibano.

A análise fitossociológica das espécies daninhas identificadas na área analisada estão descritas na Tabela 2. Analisando a quantidade de lances em que apareceram as espécies (QO) percebe-se que as espécies Xanthium strumarium L. e Cyperus rotundus L. foram as mais presentes, aparecendo em 18 dos 20 lances. Logo após elas, a segunda espécie mais presente nos lances foi a Malva sylvestris L. que apareceu em 16 lances.

0 aparecimento da espécie Xanthium strumarium L. em 18 dos 20 lances pode ser atribuído a elevada amplitude térmica diária característica da região que proporciona uma maior temperatura dos solos e acaba por favorecer a propagação desta espécie (Norsworthy e Oliveira, 2007). Segundo Rodríguez et al. (2019) um dos maiores problemas da infestação de planta de X. strumarium L. nas áreas de pastoreio é a toxicidade desta espécie que pode trazer inúmeros prejuízos a saúde dos animais.

Já a espécie Cyperus rotundus L. que também foi encontrada em 18 lances, é conhecida por ser uma planta bastante competitiva e agressiva. Essa espécie é altamente adaptada a condições de elevada temperatura e intensa luminosidade, por isso possui rápida disseminação e difícil erradicação no cariri paraibano. Além de ser favorecida pelas condições edafoclimáticas da região a $C$. rotundus L. possui várias vias de propagação (sementes, bulbos e também por meio dos engrossamentos dos rizomas) e possui a capacidade de armazenar hormônio natural capaz de estimular o enraizamento, o que facilita ainda mais sua dispersão (Moreira e Bragança, 2010; Silva et al., 2016). 
Tabela 2. Números de quadrados onde a espécie foi encontrada (QO), números de indivíduos (NI), frequência $(\mathrm{F})$, frequência relativa (Fr\%), densidade $\left(\mathrm{DM}^{2}\right)$, densidade relativa (Dr), abundancia (A), abundancia relativa (Ar) das espécies de plantas daninhas identificadas em área de pastoreio no Município de Caturité, Cariri paraibano.

\begin{tabular}{lcrcccccc}
\hline Espécie & Q0 & NI & F & Fr\% & DM & Dr & A & AR \\
\hline Amaranthus viridis L. & 11 & 54 & 0,55 & 8,15 & 2,70 & 1,47 & 4,91 & 1,57 \\
Chenopodium ambrosioides L. & 6 & 41 & 0,30 & 4,44 & 2,05 & 1,12 & 6,83 & 2,18 \\
Bidens sulphurea (Cav.) Sch. Bip. & 5 & 125 & 0,25 & 3,70 & 6,25 & 3,41 & 25,00 & 7,99 \\
Tagetes minuta L. & 2 & 13 & 0,10 & 1,48 & 0,65 & 0,35 & 6,50 & 2,08 \\
Xanthiums trumarium L. & 18 & 836 & 0,90 & 13,33 & 41,80 & 22,78 & 46,44 & 14,84 \\
Ipomoea purpurea L. & 2 & 5 & 0,10 & 1,48 & 0,25 & 0,14 & 2,50 & 0,80 \\
Cyperur Rotundus L. & 18 & 1.454 & 0,90 & 13,33 & 72,70 & 39,62 & 80,78 & 25,81 \\
Ricinus communisL. & 6 & 11 & 0,30 & 4,44 & 0,55 & 0,30 & 1,83 & 0,59 \\
Senna obtusifolia (L.) Irwin \&Barneby & 2 & 4 & 0,10 & 1,48 & 0,20 & 0,11 & 2,00 & 0,64 \\
Mimosa pudica L. & 6 & 22 & 0,30 & 4,44 & 1,10 & 0,60 & 3,67 & 1,17 \\
Malva sylvestrisL. & 16 & 100 & 0,80 & 11,85 & 5,00 & 2,72 & 6,25 & 2,00 \\
Echinochloa crusgalli (L.) P. Beauv. & 9 & 139 & 0,45 & 6,67 & 6,95 & 3,79 & 15,44 & 4,93 \\
Brachiaria decumbens cv. Basilisk & 12 & 587 & 0,60 & 8,89 & 29,35 & 15,99 & 48,92 & 15,63 \\
Cenchrus echinatus L. (CCHEC) & 4 & 26 & 0,20 & 2,96 & 1,30 & 0,71 & 6,50 & 2,08 \\
Eleusine indica (L.) Gaertn (ELEIN) & 4 & 180 & 0,20 & 2,96 & 9,00 & 4,90 & 45,00 & 14,38 \\
Richardia brasiliensis (Gomes) & 6 & 31 & 0,30 & 4,44 & 1,55 & 0,84 & 5,17 & 1,65 \\
Vitex agnus castus L. & 8 & 42 & 0,40 & 5,93 & 2,10 & 1,14 & 5,25 & 1,68 \\
\hline & 135 & 3670 & 6,75 & 100 & 183,5 & 100 & 312,99 & 100 \\
\hline
\end{tabular}

Quanto ao Número de Indivíduos (NI), dos 3.670 indivíduos quantificados, é possível observar que a espécie Cyperus rotundus L. foi a mais representativa com um total de 1.454 indivíduos $(39,61 \%$ do total de plantas quantificadas), seguida da espécie Xanthium strumarium L. com 836 indivíduos e da Brachiaria decumbens cv. Basilisk com 587.

Grandes infestações de Cyperus rotundus L. ocorrem com grande facilidade pastagens situadas no Nordeste brasileiro (Silva et al., 2017; Silva et al., 2019). Acredita-se que este fato ocorra devido a grande nocividade e rápida disseminação desta planta daninha que se adapta com facilidade e se reproduz rapidamente em praticamente todos os climas existentes no mundo (Lorenzi, 2008). Além disso, a tiririca Cyperus rotundus L. pertence à Família Cyperaceae, considerada de difícil controle após sua instalação no ambiente (Silva et al., 2017).

Já o elevado número de indivíduos da espécie Xanthium strumarium L. identificados neste estudo pode estar relacionado ao fato desta espécie ter a capacidade de explorar grandes volumes de solo se expandindo rapidamente e causando uma alta infestação o que impede o estabelecimento de outras espécies daninhas na área (Correia e Durigan, 2010).

Ainda na Tabela 2, analisando a frequência das espécies daninhas identificadas no estudo, nota-se que as espécies mais frequentes foram Xanthium strumarium L. e Cyperus rotundus L. ambas presentes em 90\% dos lances, seguidas da espécie Malva sylvestris L. presente em $80 \%$ dos lances.Em contrapartida, as espécies Ipomoea purpurea L. e Senna obtusifolia (L.) Irwin \& Barneby foram as menos frequentes encontradas em apenas 10\% dos lances. Esse mesmo padrão também foi observado para as frequências relativas. Esses resultados denotam uma distribuição irregular das espécies, o que segundo Lima et al. (2017) indica grande ocorrência de competição na pastagem investigada.

A Densidade total de plantas daninhas na pastagem analisada foi de 183,5 plantas $/ \mathrm{m}^{2}$, deste total, a espécie Cyperus rotundus L. representou 39,29\%, com Densidade 
igual a $72,70 \mathrm{~m}^{2}$, seguida das espécies Xanthium strumarium L. $\left(41,80 \mathrm{~m}^{2}\right)$ e Brachiaria decumbens cv. Basilisk $\left(29,35 \mathrm{~m}^{2}\right)$. Observou-se o mesmo padrão para o parâmetro Densidade relativa, assim, estas espécies foram nesta ordem as populações mais numerosas dentro da fitocenose estudada (Tabela 2).

Estas mesmas espécies, Cyperus rotundus L. $(A=80,78$ e AR= 25,81) Brachiaria decumbenscv. Basilisk $(A=48,92$ e $A R=15,63)$ e Xanthium strumarium $\mathrm{L} .(\mathrm{A}=46,44$ e $\mathrm{AR}=$ $14,84)$, também foram as mais abundantes na comunidade, fator que segundo Sousa (2018) pode indicar as ações necessárias para controle destas espécies na área.

Corroborando com os maiores valores encontrados para Densidade e Abundância, é possível verificar na Figura 2 que as espécies com os maiores Índices de Importância Relativa também foram Cyperus rotundus L. (78,76\%), Xanthium strumarium L. (50,95\%) e Brachiaria decumbens cv. Basilisk (40,51\%). Essas espécies têm em comum fácil adaptação as condições edafoclimáticas da região, além de alto potencial reprodutivo, agressividade e competitividade, reforçando-as assim como espécies que merecem uma certa urgência para o controle, requerendo maior atenção na pastagem estudada (Macedo et al., 2018).

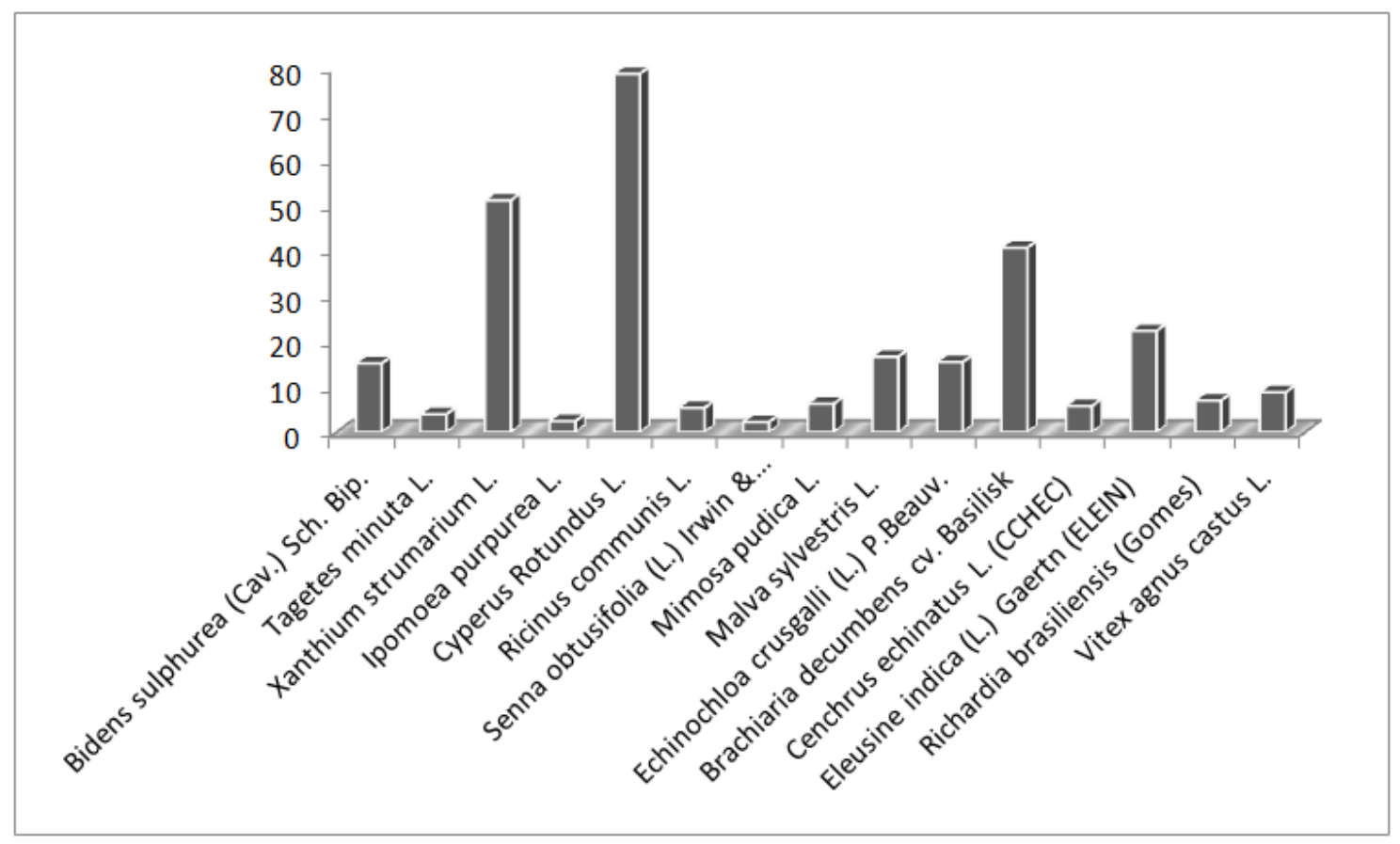

Figura 2. Índice de Importância Relativa (IVr\%) Distribuição das espécies de plantas daninhas identificadas em área de pastoreio no município de Caturité, Cariri paraibano.

A grande expressividade destas espécies dentro da fitocenose avaliada também pode ser resultado da preferência alimentícia dos animais por determinadas espécies, pois, nas áreas de pastoreio a herbivoria pode ocasionar o desequilíbrio da competição e consequentemente favorecer as espécies menos quistas pelos animais (Brighenti et al., 2016). 


\section{Conclusão}

As famílias botânicas mais representativas na área analisada foram Poaceae, Asteraceae e Amaranthaceae.

Entre as espécies daninhas identificadas na pastagem foi constatada uma distribuição irregular, indicando a existência de concorrência entre as populações daninhas e evidenciando uma degradação da área.

As espécies Cyperus rotundus L., Xanthium strumarium L. e Brachiaria decumbens cv. Basilisk, destacaram-se como aquelas que merecem maior atenção no controle.

\section{Referências}

Ab'Saber, A. N. Os domínios da natureza no Brasil: potencialidades paisagísticas. São Paulo: Ateliê, 2003.

Aguiar, S. C.; Querino, L. A. L.; Silva, P. F.; Lima, V. L. A. Vulnerabilidade da palma forrageira e pecuária bovina no Estado da Paraíba frente ao ataque da cochonilha do carmim. REGNE, v. 5, p. 104-115, 2019. https://doi.org/10.21680/2447-3359.2019v5n0ID17977

Bezerra, A. K. C. Caracterização da atividade leiteira nos Municípios de Barra de Santana e Boqueirão - Cariri paraibano. Areia: Universidade Federal da Paraíba, 2016. (Monografia de graduação).

Braga, R. R.; Cury, J. P.; Santos, J. B.; Byrro, E. C. M.; Silva, D. V.; Carvalho, F. P.; Ribeiro, K. G. Ocorrência de plantas daninhas no sistema lavoura-pecuária em função de sistemas de cultivo e corretivo de acidez. Revista Ceres, v. 59, n. 5, p.646-653, 2012. https://doi.org/10.1590/S0034-737X2012000500010

Brandão, M.; Brandão, H.; Laca-Buendia, J. P. A mata ciliar do Rio Sapucaí, Município de Santa Rita do Sapucaí-MG: fitossociologia. Daphne, v. 8, n. 4, p. 36-48, 1998.

Braun-Blanquet, J. Fitossociologia: bases para el estudio de las comunidades vegetales. Madrid: H. Blume, 1979.

Brighenti, A. M.; Castro, C.; Gazziero, D. L. P.; Adegas, F. S.; Voll, E. Cadastramento fitossociológico de plantas daninhas na cultura do girassol. Pesquisa Agropecuária Brasileira, v. 38, n. 5, p.651-657, 2003. https://doi.org/10.1590/S0100204X2003000500014

Brighenti, A. M.; Calsavara, L. H. F.; Muller, M. D.; Varotto, Y. V. G. Fitossociologia de plantas daninhas em áreas de integração lavoura-pecuária. Livestock Research Rural Development, v 28, n. 12, Article \#214, 2016. Disponível em: <http://www.lrrd.org/lrrd28/12/ferr28214.html>. Acesso em: 06 jan. 2020.

Cidade Brasil. Município de Caturité. 2019. Disponível em: <https://www.cidadebrasil.com.br/municipio-caturite.html>. Acesso em: 06 jan. 2019.

Costa, J. P.; Mesquita, M. L. R. Floristic and phytosociology of weeds in pastures in Maranhão State, Northeast Brazil. Revista Ciência Agronômica, v. 47, n. 2, p. 414-420, 2016. https://doi.org/10.5935/1806-6690.20160050

Correia, N. M.; Durigan, J. C. Controle de plantas daninhas na cultura de soja resistente ao glyphosate. Bragantia, v. 69, n. 2, p. 319-327, 2010. https://doi.org/10.1590/S000687052010000200009

Dias-Filho, M. B. Degradação de pastagens: o que é e como evitar. Brasília: EMBRAPA, 2017. 
Dominschek, R.; Deiss, L.; Lang, C. R.; Moraes, A.; Pelissari, A. High sunflower densities as a weed control strategy in an integrated crop-livestock system. Planta Daninha, v. 37, 2019. https://doi.org/10.1590/s0100-83582019370100072

Ferreira, E. A.; Paiva, M. C. G.; Pereira, G. A. M.; Oliveira, M. C.; Silva, E. B. Fitossociologia de plantas daninhas na cultura do milho submetida à aplicação de doses de nitrogênio. $\begin{array}{lllll}\text { Revista de Agricultura Neotropical, } & \text { v. 6, } & \text { n. 2, } & \text { p. 100-107, }\end{array}$ https://doi.org/10.32404/rean.v6i2.2710

Galvão Júnior, J. G. B.; Rangel, A. H. N.; Guilhermino, M. M.; Novaes, L. P.; Medeiros, H. R. Perfil dos sistemas de produção de leite bovino no Seridó Potiguar. Holos, v. 2, p. 130-141, 2015. https://doi.org/10.15628/holos.2015.1913

IBGE - Instituto Brasileiro de Geografia e Estatística. Cidades. Panorama Caturité. 2019. Disponível em: <https://cidades.ibge.gov.br/brasil/pb/caturite/panorama>. Acesso em: 06 jan. 2019.

Lamego, F. P.; Caratti, F. C.; Reinehr, M.; Gallon, M.; Santi, A. L.; Basso, C. J. Potencial de supressão de plantas daninhas por plantas de cobertura de verão. Comunicata Scientiae, v. 6, n. 1, p. 97-105, 2015. https://doi.org/10.14295/cs.v6i1.470

Lara, J. F. R.; Macedo, J. F.; Brandão, M. Plantas daninhas em pastagens de várzeas no Estado de Minas Gerais. Planta Daninha, v. 21, n. 1, p.11-20, 2003. https://doi.org/10.1590/S0100-83582003000100002

Lima, A. K. O.; Araujo, M. S. B.; Santos, N. F. A.; Melo, M. R. S.; Sousa, V. Q.; Pedroso, A. J. S.; Borges, L. S.; Freitas, L. S. Composição florística e fitossociologia de plantas espontâneas em pastagens do gênero Brachiaria (Syn. Urochloa) no nordeste paraense. $\begin{array}{llll}\text { Agroecossistemas, } & \text { v. } 9, & \text { n. } 2, & \text { p. 339-349, }\end{array}$ https://doi.org/10.18542/ragros.v9i2.4993

Lorenzi, H. Manual de identificação e controle de plantas daninhas: plantio direto e convencional. 7. ed. Nova Odessa: Instituto Plantarum, 2014.

Luna, R. G.; Andrade, A. P.; Souto, J. S.; Luna, J. G. Análise florística e fitossociológica de quatro áreas de caatinga sob diferentes densidades de caprinos no Cariri Paraibano, Brasil. Revista Brasileira de Gestão Ambiental e Sustentabilidade, v. 5, n. 9, p. 191-229, 2018. https://doi.org/10.21438/rbgas.050913

Macedo, N. C.; Portela, G. F.; Diniz, K. D.; Rezende, L. P. Levantamento fitossociológico de plantas daninhas em pastagem capim massai (Panicum maximum JACQ.) no Município de Sambaíba-MA. Global Science and Technology, v. 11, n. 2, p.78-87, 2018.

Moreira, H. J. C.; Bragança, H. B. N. Manual de identificação de plantas infestantes: cultivos de verão. Campinas: 2010. Disponível em: <https://www.embrapa.br/trigo/transferencia-de-tecnologia/parceria-ocb//asset_publisher/NcEJiyaj6Jrz/document/id/13060932>. Acesso em: 06 jan. 2019.

Norsworthy, J. K.; Oliveira, M. J. Tillage and soybean canopy effects on commom cocklebur (Xanthium strumarium) emergence. Weed Science, v. 55, n. 5, p. 474-480, 2007. https://doi.org/10.1614/WS-07-003.1

Oliveira, A. R.; Freitas, S. P. Levantamento fitossociológico de plantas daninhas em áreas de produção de cana-de-açúcar. Planta Daninha, v. 26, n. 1, p. 33-46, 2008. https://doi.org/10.1590/S0100-83582008000100004

Oliveira, F. C. S. Interferência das plantas daninhas na produtividade e nutrição da cultura do milho verde em São Luís- MA. Jaboticabal: Universidade Estadual Paulista "Julio de Mesquita Filho", 2018. (Dissertação de mestrado). 
Paulino, V. T.; Schumann, A. M.; Silva, S. C.; Rasquinho, N. M.; Santos, K. M. Impactos ambientais da exploração pecuária em sistemas intensivos de pastagens. Informe Agropecuário, v. 33, n. 266, p. 17-24, 2012.

Rodríguez, F. I. P.; Sardiñas, J. A. B.; Reyes, R. L.; Dunas, C. C. Identificación de plantas tóxicas en entidades pecuarias, región central de Cuba. Anais da IX Conferencia Científica Internacional Desarrollo Agropecuario y Sostenibilidad e do IX Simposio de Medicina Veterinaria y Zootecnia, Universidad Central “Marta Abreu” de Las Villas, 2019.

Silva, A. F.; Silva, M. C. B. C. Agricultura no Nordeste semiárido e os resíduos orgânicos aproveitáveis. Revista Equador, v. 5, n. 2, p. 102-119, 2016.

Silva, A. B.; Mello, M. R. F.; Sena, A. R.; Lima Filho, R. M.; Leite, T. C. C. Efeito do extrato de Cyperus rotundus L. no enraizamento de estacas de amoreira-preta. Revista CIENTEC, v. 8, n. 1, p. 1-9, 2016.

Silva, J. M. F.; Sarmento, H. G. S.; Araújo, H. T. N.; Oliveira, A. B.; Lamartine, L. S. C. Weeds in pastures: A phytosociological approach in Ceará areas. Agrarian, v. 12, n. 45, p. 279-285, 2019. https://doi.org/10.30612/agrarian.v12i45.7048

Silva, J.; Cunha, J. L. X. L.; Oliveira, F. S.; Silva, R. G.; Gomes, C. B.; Carvalho, A. P. V.; Silva Júnior, A. B.; Silva, C. A. Composição do banco de sementes em diferentes profundidades de uma área cultivada com capim aruana. Agrarian, v. 11, n. 40, p. 140-149, 2018.

Silva, M. R. M.; Peixoto, M. C. R.; Santos, R. N. V.; Cardoso, M. P.; Pires, H. P. Banco de sementes de plantas espontâneas após cultivo do milho sob cobertura de palha de babaçu. Cadernos de Agroecologia, v. 13, n. 1, 2018. Disponível em: <http://cadernos.abaagroecologia.org.br/index.php/cadernos/article/view/1835/139>. Acesso em: 06 jan. 2019.

Travassos, I. S. Florestas brancas do semiárido nordestino: desmatamento e desertificação no cariri paraibano. João Pessoa: Universidade Federal da Paraíba, 2012. (Dissertação de mestrado).

Tuffi Santos, L. D.; Santos, I. C.; Oliveira, C. H.; Santos, M. V.; Ferreira, F. A.; Queiroz, D. S. Levantamento fitossociológico em pastagens degradadas sob condições de várzea. Planta Daninha, v. 22 , $\quad$ n. $3, \quad$ p. 343-349, 2004. https://doi.org/10.1590/S010083582004000300003

Informação da Licença: Este é um artigo Open Access distribuído sob os termos da Licença Creative Commons Attribution, que permite uso irrestrito, distribuição e reprodução em qualquer meio, desde que a obra original seja devidamente citada. 